\title{
BMA urges plan to tackle backlog of patients awaiting non-covid treatment
}

\author{
Elisabeth Mahase
}

The BMJ

The government urgently needs to set out a plan to reduce the huge backlog of patients waiting for NHS treatments unrelated to covid-19 in the wake of the pandemic, the BMA has said.

The call came as the BMA released the results of its latest survey of over 8000 doctors. It found that more than half (3754 of 7238) were either not very confident or not confident at all that their department would be able to manage patient demand as NHS services resumed. ${ }^{1}$

"The government must be honest with the public about the surge to come and start meaningful conversations with frontline clinicians about how we can, together, begin to tackle the backlog," said the BMA's chair of council, Chaand Nagpaul. "Covid-19 has brought with it the worst health crisis in a century. The NHS must not return to its previous perilous state."

The survey indicates that the expected rise in demand has already begun: over $40 \%$ (3132 of 7269) of doctors said that demand had increased significantly in the past week, and around $14 \%$ (1003) said it had already exceeded pre-covid levels.

Meanwhile, more than a quarter of doctors (1966 of 7289) said there had been no engagement with them over how to manage the increase in demand in their place of work or local area.

Nagpaul said, "Resources were diverted to covid-19 efforts at the expense of other care and patients. The impact on patients cannot be underestimated-with figures earlier this week showing more than two million people waiting for cancer care alone, with overall waiting lists projected to hit seven million by autumn. Meanwhile, ONS statistics this week estimated that, tragically, there have been more than 56000 excess deaths during the epidemic in England and Wales, with almost a quarter of these not being due to covid-19 itself."

He added that the positive improvements made during the pandemic, such as reduced paperwork, bureaucracy, and unnecessary regulation, and new ways of working, including further use of video technology and remote working, must be retained.

The survey also highlighted the pandemic's effect on doctors' wellbeing. More than two fifths (3217 of 7821) said they had been suffering from work related mental health issues, and $70 \%$ of these (2235) said it had been worse during the pandemic.

The BMA has set out how the government could tackle the rising demand. This includes provision of up-to-date data on waiting lists, the prevalence of certain conditions, and health inequalities. The government should also commit itself to giving the NHS the resources it needs to tackle the backlog, as well as the capacity to meet demand in the long term, and it must "retain, support, and protect the valuable staff who have given their all in fighting the pandemic, prioritising their wellbeing and mental health."

1 BMA. Covid-19 tracker survey wave 5.4 June 2020. https://www.bma.org.uk/media/2553/ embargoed-04062020-tracker-survey-5-results.pdf.

This article is made freely available for use in accordance with BMJ's website terms and conditions for the duration of the covid-19 pandemic or until otherwise determined by BMJ. You may use, download and print the article for any lawful, non-commercial purpose (including text and data mining) provided that all copyright notices and trade marks are retained.

https://bmj.com/coronavirus/usage 